\title{
Environmental Designs for Reading From Imaging Work Stations: Ergonomic and Architectural Features
}

\author{
Steven C. Horii, Howard N. Horii, Seong Ki Mun, Harold R. Benson, and Robert K. Zeman
}

\begin{abstract}
Despite the rapid progress made in the electronic design of imaging work stations for medicine, much less effort has gone into the design of environments in which such systems will be used. Based on studies of radiologist film reading sessions, considerable time will be spent working at such viewing systems. If the rooms in which the work stations are placed are not conducive to comfortable work, it will certainly not favor electronic viewing over film reading. In examining existing reading environments, it is also apparent that they are not optimal, even for film. Since some of the problems for film and electronic viewing overlap, such as heat generation (by the alternators, viewboxes, or work station electronics) and glare from light sources, it should be possible to develop solutions that are applicable to both environments, or to rooms that will feature both viewing systems. This paper will discuss some of the approaches to designing environments in which viewing of images is supported by the room architecture and engineering, rather than being degraded by it. To illustrate these points a design, based on the constraint of a real room size and available architectural materials, will be developed.
\end{abstract}

(C) 1989 by W.B. Saunders Company.

$\mathbf{A}^{\mathrm{T}}$ THE Society of Photo-Optical Instrumentation Engineers (SPIE) medical imaging meeting last year, we presented a paper that examined ergonomic features of radiology workstations and reading environments. ${ }^{1}$ Both prior to and since that time, extensive work has been done on the design of such work stations to better suit the tasks performed by medical imaging specialists, and to make such performance more efficient from the viewpoints of human factors and productivity. ${ }^{2-10}$ In particular, analysis of the work patterns of radiologists ${ }^{7-9}$ have been combined with advances in person-computer interaction (user interfaces) resulting in viewing and reading systems that are far ahead of older aproaches. ${ }^{6,8,10}$

In addition to the workstation itself, we also examined the environment in which such equip-

From the Department of Radiology, Georgetown University Hospital, Washington, DC, and The Grad Partnership, Newark, NJ.

Address reprint requests to Steven C. Horii, MD, DepartCent of Radiology, Georgetown University Hospital, 3800 Reservoir Rd, NW, Washington, DC 20007.

(c) 1989 by W.B. Saunders Company.

0897-1889/89/0203-0003\$03.00/0 ment will be used. Unfortunately, aside from the reports of ter Haar Romeny ${ }^{11}$ and Balter and Janower, ${ }^{12}$ little attention has been given to such environmental design in the medical imaging literature. The problem raises both architectural and engineering concerns, and requires considerable use of human-factor design principles. We have had the opportunity to work on the design of a reading area within the department. This area will support conventional film as well as picture archiving communication systems (PACS) workstation reading, and will be used by the Abdomi nal Imaging Division. As such, a combination of plain film, computed tomography (CT), magnetic resonance imaging (MRI), and ultrasound cases will be interpreted. This new reading room is a renovation of an existing space, and so is subject to the constraints of existing bearing walls, columns, and major ductwork.

We will examine the design for this space with discussion of the principles used.

\section{WORK SPACE DESIGN}

There are two excellent books on designing radiology departments, ${ }^{13,14}$ and both discuss some elements of reading room design. Both volumes were written before electronic PACS became a serious alternative to film-based operation. However, some of the basic design considerations are not altered by switching to soft-copy reading.

Often a first consideration is to determine the amount of space available to house the reading area. Finding space is a problem in any health care facility we have seen. Even if a new structure is being built, space may be at a premium because of high construction costs or available lot size. More commonly, one will be faced with finding space in an existing facility, or modifying the facility that is available. Scott ${ }^{14}$ recommends a space of about $8 \times 10 \mathrm{ft}(2.6 \times 3 \mathrm{~m})$ for each person reading. Since a four-panel viewbox array, an alternator, and a four-monitor PACS workstation have about the same width $(5$ to $7 \mathrm{ft}$ or 1.6 to $2.3 \mathrm{~m}$ ), this estimate is a reasonable one. It certainly allows for the one or two other people usually present in a teaching hospital setting, and can accomodate more for shorter periods of time. 
The room we will be working with consists of two spaces, the larger $20 \times 24 \mathrm{ft}(6 \times 7.3 \mathrm{~m})$ and the adjacent smaller space $7 \times 10 \mathrm{ft}(2.1 \times 3 \mathrm{~m})$. The outer perimeter of the space is constrained by bearing walls and other existing services that cannot be relocated. Figure 1 shows the plan of the existing space.

The main activity in a reading room is interpreting examinations. However, such rooms may be used often for short conferences, consultation with referring physicians, and teaching. Unless there is a requirement to provide services other than for those associated with film reading, it is simpler to design based on the predominant use. Combination-use rooms often, but do not always, involve some compromise of one or the other function. For example, in a reading room also used for lengthy conferences, slide projection requirements may preclude optimum placement of view boxes or light-baffling walls. The room we are renovating will be used primarily for film reading. Associated teaching and consultation are currently supported at the reading stations and will be in the future. Despite the common picture of radiologists relatively fixed at their reading stations, there is a lot of movement of people in and out of the reading area. The radiologist may move to another reading area for consultation, leave temporarily to attend to a patient having a procedure done, or move to a

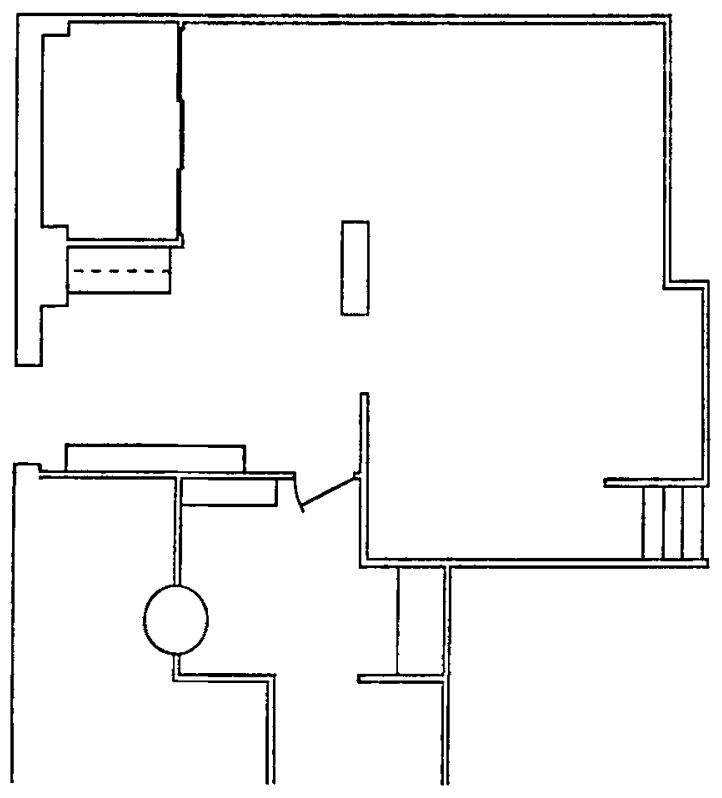

Fig 1. Floor plan of the existing reading room. different place to make or answer a phone call. Similar actions are performed by the house staff, and different ones by referring physicians and file room personnel. All of this points to a high-traffic area, so that in these ways, the use defines the required access.

Fire and building codes will fix the number and placement of exits from a space. In addition to emergency egress, access is also involved with movement of people to other areas as they do their work. A facility such as a main or large satellite reading room needs to be accessible to virtually anyone in the department. It should not, however, be located so as to serve as a general traffic corridor, nor should such use be encouraged, as it is disruptive to the work of the radiologists. Aside from the radiologists working in the room and referring physicians coming in to look at examinations, there are technologists, clerks, transcription personnel, secretaries, administrators, and housekeepers (this list being based on access frequency and not on job importance, though cynics might assume otherwise) who regularly need to go to the reading area. It is impossible to make such a facility easily accessible to all of these people. Since the radiologists are most dependent on the space, some thought should be given to optimizing the location of the room for access to the areas they need to reach often. In the instance of our reading area, it is located proximate to the CT rooms, the ultrasound laboratory, and the Abdominal Division offices. In fact, it is relatively central to these, with CT across the north corridor, ultrasound to the west side, and the offices south. The MRI facility is located remotely, due to the usual siting problems of such facilities, but is a short walk and elevator ride away.

In support of the uses of the reading room, we need to consider supporting services. Heating, ventilation, and air conditioning (HVAC), electrical power, communications, illumination, and acoustic control are typical factors that we will include with services. All of these will be discussed in more detail in subsequent sections of this article. While all of these are part of the environment, electrical power requirements and communications systems have less of an immediate impact on bodily comfort than the other listed items. Providing these services for a workspace requires the coordination of several types of 
designers and contractors. A good architect will work with the client and the client's contractors so that the construction proceeds as smoothly as possible. In our design stage, we have evaluated the services necessary and will be proceeding with additional engineering detail needed for actual construction.

At the base of any new or renovated workspace design is the budget allotted for the project. This may determine the kinds of solutions to problems that can be realistically implemented. Again, a good architect serves the client by being able to provide a number of possible solutions to any problem, so that an optimum design can be achieved for any budget level.

\section{TASKS AND ENVIRONMENT}

The major task to be supported in a reading room is the interpretation of medical images. However, this consists of a number of smaller tasks. A number of these were described in a very detailed fashion in the paper by Rogers, ${ }^{15}$ and in a more general fashion by Mun. ${ }^{16}$ Aside from looking at images on alternators or workstations, a large amount of writing is done, results are dictated, and teaching is often incorporated into these processes. This means that facilities to support these activities must be provided, and features of the room should not hinder any task to a significant degree, or preferably not hinder any task at all. Some of these actions have requirements that are contrary to others. For example, image reading is best done with as little ambient light as possible, but some light is needed for writing and for searching through film folders.

The devices that need to be located in the room are also based on the work to be done. Film alternators and workstations are the equipment we have designed. However, report generation requires some form of dictation system, and consultation requirements force heavy dependence on telephones. Because we have found that telephone use may be quite frequent, it would benefit users if the phones were located on the workstation or alternator tables, or were at least within reach without standing up.

The environment can be thought of as a combination of the physical space or structure, the services provided, and the equipment and people within. In addition to the size and layout of the room, there are ceiling constraints (fixed ducting) and flooring systems (raised flooring) to be considered. The fixed ducting to some extent affects placement of lighting fixtures. The raised flooring is an advantage because it allows for very easy re-routing of cables, but does require more maintenance than plain flooring (the supports may get out of alignment, resulting in panels that rock a bit). The floor plan of our existing space with the equipment as located is shown in Fig 2. The changes made to the layout will involve moving the existing neuroradiology reading area to a different location (which will probably not involve equipment relocation), moving GI/GU into the room, and relocating the two Image Management and Communications System (IMACS) work stations for better user access. Figure 3 shows the changes to be made to the walls and alternator locations. Not shown are a number of storage shelves and cabinets to be used to house books, selected films, and other items used by the radiologists. This design is felt to be adequate given that approximately the same number of people will be using the room, and no new equipment is being added. This latter factor means that new electrical power and HVAC changes are not required for the larger reading area. The IMACS work station (CommView EDW4, AT\&T, West Long Branch, NJ) for ultrasound is in a new location, and its heat load

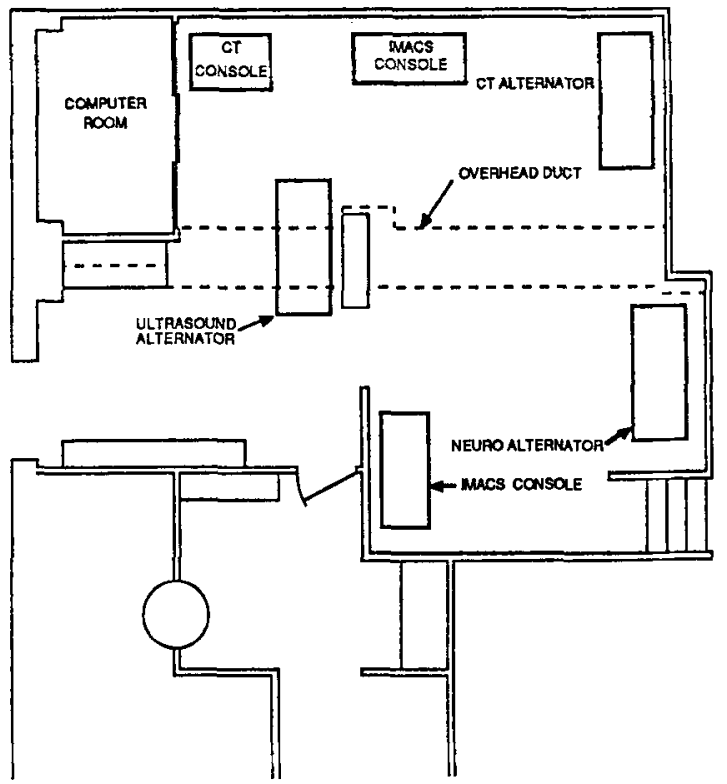

Fig 2. Existing reading room with major equipment. 


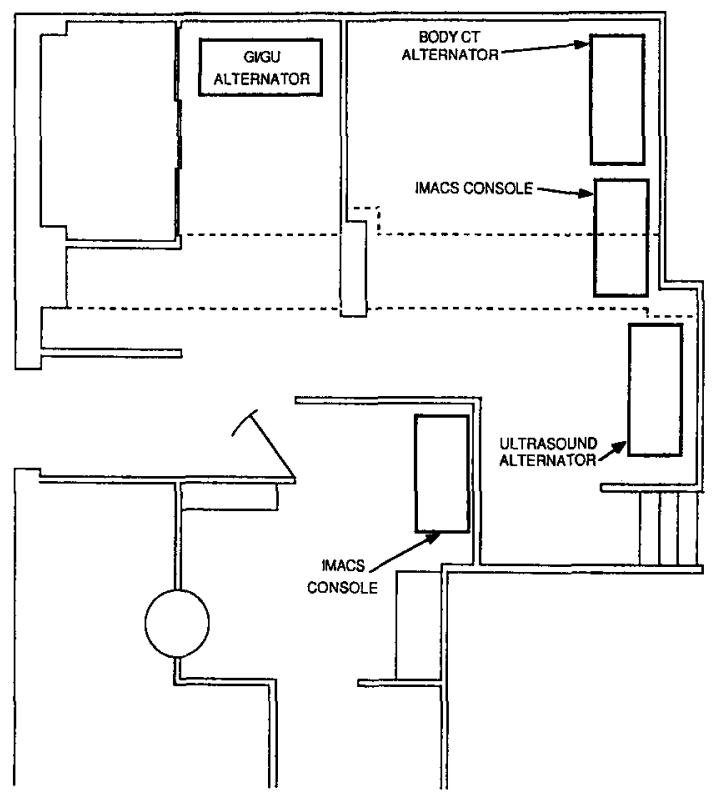

Fig 3. Reading room redesign with equipment placement.

of $8,500 \mathrm{BTU} / \mathrm{h}(2,144 \mathrm{kcal} / \mathrm{h})$ will be considered.

Structural requirements may also have to include floor loading and vibration studies, and some local building codes will affect the impact of these issues on any design. Addition of heat sources or the expansion of a facility for a larger number of people will have to take these conditions into account when considering HVAC requirements.

\section{COMFORT}

Most important to the users of any given space is how comfortable they will be when using it. Quite separate from the user interface issues raised by electronic workstations are those things that directly affect comfort. These factors include seating, heat, noise, and light. Though people can operate within wide ranges of these varibles, adverse values will impair function either temporarily or permanently (chronic exposure to high noise levels, for example, can do both). In some instances, the degree of impairment may not be noticed by the person working, but various measurements will show distinct performance losses. ${ }^{17}$

We have found that reading sessions may last from fractions of an hour to four hours, ${ }^{18}$ so that comfortable seating is a must. The "ergonomic" design chair has become quite popular in offices in which video display terminals (VDTs) are used. The major features of these chairs are adjustability, good low back (lumbar) support, arm rests (for keyboard users), and good padding. There are apparently a set of American National Standards Institute standards for such chairs, though the authors have not seen them. We have found that this type of chair is acceptable to the radiologists, and are presently in use in some reading rooms and offices.

Having taken into account the equipment and personnel heat load, the HVAC design should maintain the room temperature in a comfortable range. For most people, this range changes with seasons, but is approximately 63 to $71^{\circ} \mathrm{F}(17.2$ to $\left.21.7^{\circ} \mathrm{C}\right)$ in winter, and 65 to $75^{\circ} \mathrm{F}(18.3$ to $23.9^{\circ} \mathrm{C}$ ) in summer. ${ }^{19}$ The relative humidity of the air affects perceived temperature, and the most comfortable range is from about $20 \%$ to $60 \%$ at $75^{\circ} \mathrm{F}^{20}$ Electronic equipment is also constrained by temperature and humidity, but will generally operate well in the same ranges as those that are comfortable for people.

Sound is one of the environmental factors that is highly subjective. Most of us know that sounds may or may not be irritating, depending on the context. A newborn's first cry is probably music to most ears, but a child's cry that wakes you in the middle of the night is hardly so. It is sound quality as well as loudness and context that alter its perception. Noise is thought of as unwanted sound. Despite these problems defining noise, most designers think that an office-type workspace has a noise threshold of about $58 \mathrm{~dB}^{21}$ There are specific Occupational Safety and Health Administration limits for sound exposures, but these are for sound levels far above those that should be encountered in any reading room environment. Standard methods for noise control are found in a selection of materials used for ceiling, floor, and walls. Acoustical ceiling and carpet are excellent sound absorbers, and matte wall finishes or even acoustic absorption panels on the walls are better than plain gloss or semi-gloss wall treatments.

We feel that lighting is one of the most critical issues to be faced in reading room design. This is particularly true for rooms in which CRT displays will be read because their brightness is usually less than that of film on a viewbox. As 
described previously, the tasks of reading images and writing notes will have opposite lighting requirements in a radiology reading room. Aside from general room illumination and task lights, the image displays themselves (whether CRT or alternator) are a source of additional light. The problem is that the lighting may result in glare from CRT screens or from film, and this may impair reading by reducing contrast sensitivity of the eye or by fatiguing the iris. ${ }^{22}$ The curved screens of CRTs are an additional complication because they reflect light sources from a wider angle than a flat screen or film. In our reading room at present, most task lighting is stray light from the alternators. All the ceiling lights are usually turned off. This poses some problems for the IMACS workstation as some illumination is needed to see the keyboard and control panel.

Glare is a problem for at least two reasons. First, glare causes the pupil to constrict more than it normally would if there were no glare. This results in less of the illuminated information getting to the retina. Second, the glare source can result in veiling glare within the eye itself. This results from the scattering of light by the vitreous portion of the eye, and is increased when extraneous light enters the eye.

Lighting design is often aimed at achieving some brightness on the work surface and is adjusted for the task to be performed. This rarely takes into account the problems posed by glare, but with increasing use of VDTs, some lighting manufacturers are designing systems that control the output light beam. Figure 4 is a schematic illustration of the glare problem posed by a diffuse light source, and Fig 5 shows how this is reduced by using a directional luminaire (the

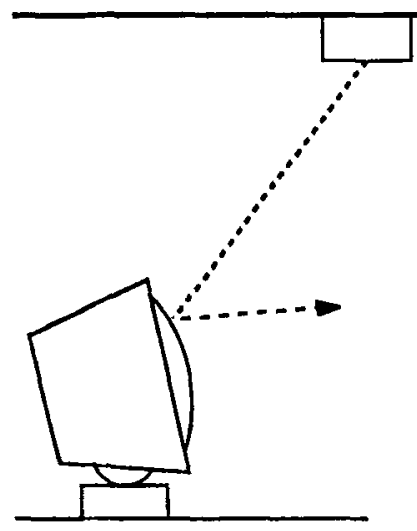

Fig 4. Screen glare from a diffuse luminaire.

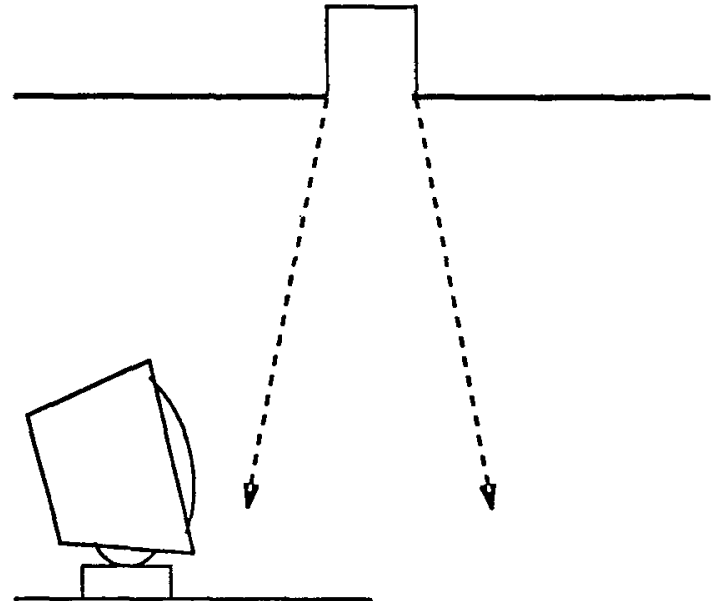

Fig 5. Reducing glare with a directional luminaire.

term for a lamp plus fixture). Tilt and swivel monitors help relieve the glare problem to some degree, but may not be practical for all workstations.

Other methods of reducing the reflection from CRT screens include etching the envelope glass, coating the glass, and placing filters or screens over the tube. Etching the glass reduces specular reflection, but also blurs the image on the phosphor, reducing the apparent spatial resolution. Antireflection coatings work well, but suffer from sensitivity to fingerprints and smudges. Frequent cleaning of such screens is a must. Filters work by attenuating the light reflected off the tube more than the light coming from the tube, since the reflected light passes through the filter twice. Filters themselves are subject to reflection from their surfaces. Screens act as collimators, but are subject to collecting dirt. For high-resolution displays, the mesh of the screen may be visible. The monitors in our workstations all use antireflection coatings.

One consistent problem we have seen in reading room design is the placement of viewboxes and alternators. If at all possible, placement on opposing walls with the reading surfaces facing each other should be avoided. Even placement on orthogonal walls can result in glare problems for anyone not viewing normal to the illuminator surface. It is unfortunate that even some texts ${ }^{23}$ violate this principle in example designs. This is not a problem if the two sets of viewboxes or alternators are never used simultaneously, since the unused one can simply be turned off. 


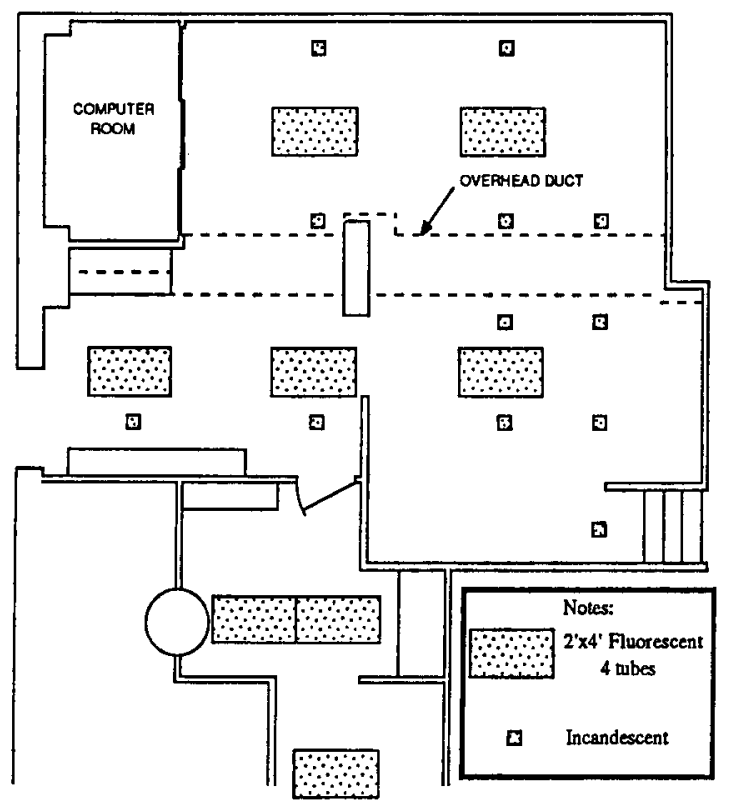

Fig 6. Existing reflected ceiling plan.

We have given a great deal of attention to the lighting problem. The overload ambient lighting plan uses a luminaire design (Lithonia Optimax, National Service Industries, Inc, Conyers, GA) that has been widely used in VDT-intensive offices. A number of lighting manufacturers are now addressing this problem so that architects have a choice of vendors. Overhead lighting on dimmers can further control brightness. Local

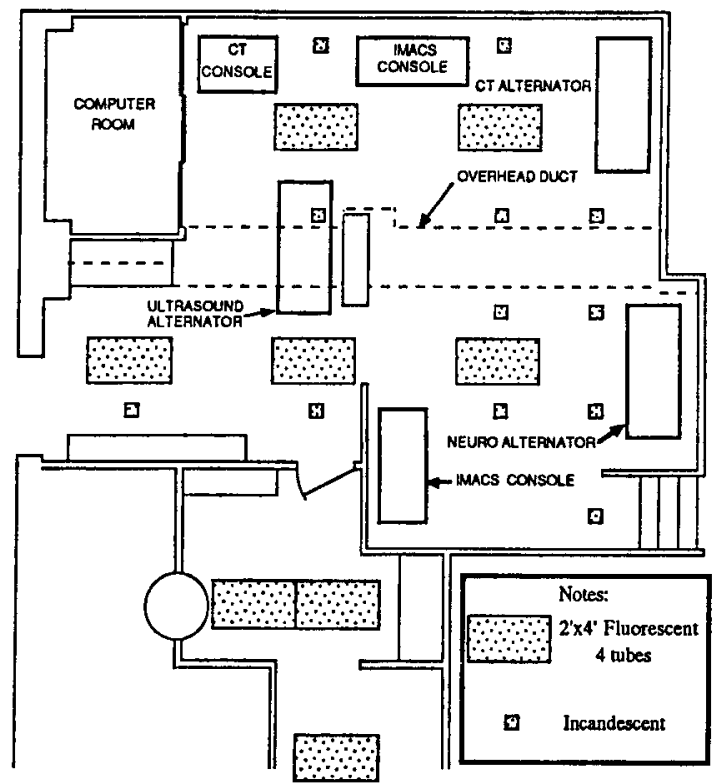

Fig 7. Existing reflected ceiling plan and major equipment. fire codes may restrict very low illumination levels, and some consideration must be given to special lighting for exits in this regard. Also, good solutions for task lighting at a workstation are difficult to find. One problem is that some task lighting, when bright enough to assist reading or writing, illuminates a user's face or clothing enough for them to become a glare source.

Figure 6 shows the existing reflected ceiling plan and light sources. Figure 7 puts this together with the equipment in the room. None of the ceiling lights is directional, and this is a major reason for turning them all off during reading sessions. Figure 8 shows the proposed reflected ceiling plan using the highly directional luminaires. We would provide separate switch/ dimmer controls for the luminaires nearest the equipment so that their brightness could be individually adjusted.

\section{CONCLUSION}

We have tried to provide an outline of room design based on conventional architectural principles applied to the problems posed by electronic image displays. In addition to the usual concerns about the equipment (powering it, cooling it, and paying for it), the most successful environments for the equipment will be those in which human factors have been given equal or more consideration than equipment requirements alone.

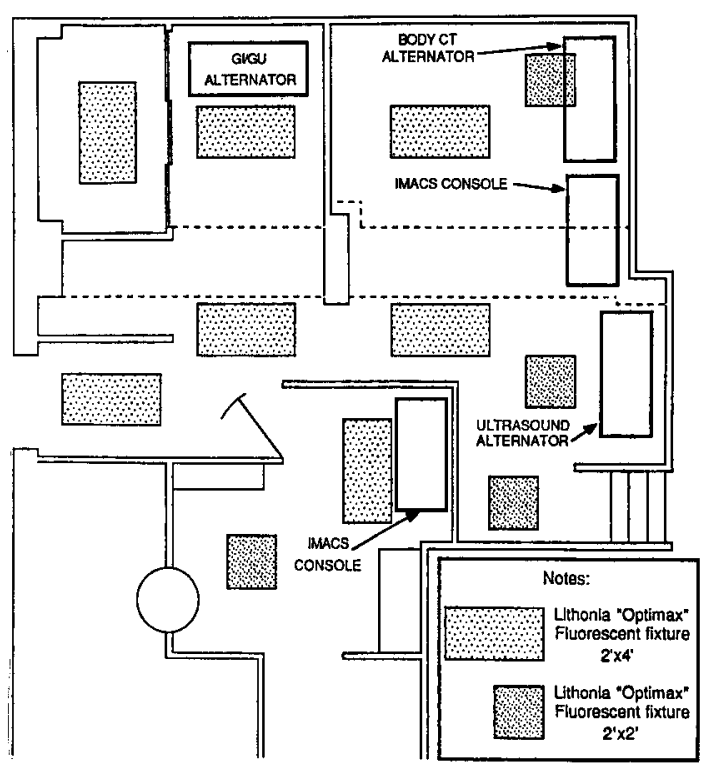

Fig 8. Proposed reading room design. 


\section{REFERENCES}

1. Horii SC, Horii HN, Kowalski, P: An eclectric look at viewing station design. Proc SPIE vol 914, Medical Imaging II, 1988, pp 920-928

2. McNeill KM, Fisher III HD: A model for radiologic workstation user interface design. Proc SPIE vol 767, Medical Imaging I, 1987, pp 713-716

3. Taira RK: Operational characteristics of pediatric radiology image display stations. Proc SPIE vol 767 , Medical Imaging I, 1987, pp 571-576

4. Schuttenbeld HHW, ter Haar Romeny BM: Design of a user interface for a PACS viewing station. Proc SPIE vol 767, Medical Imaging I, 1987, pp 844-848

5. Beard D, Pizer SM, Rogers D, et al: A prototype single-screen PACS console development using human computer interaction techniques. Proc SPIE vol 767, Medical Imaging I, 1987, pp 646-653

6. Fuchs, H, Pizer SM, Creasy JL, et al: Interactive, richly cued shaded display of multiple 3D objects in medical images. Proc SPIE vol 914, Medical Imaging II, 1988, pp 842-849

7. McNeill KM, Seeley GW, Maloney K, et al: Comparison of digital workstation and conventional reading for evaluation of user interfaces in radiology. Proc SPIE vol 914, Medical Imaging II, 1988, pp 872-876

8. Beard D, Creasy JL, Symon J, et al: Experiment comparing film and the FilmPlane radiology workstation. Proc SPIE vol 914, Medical Imaging II, 1988, pp 933-937

9. Good BC, Cooperstein LA, Gur D: Radiologists' perceptions of and preferences for a concise history form during radiologic interpretation. Proc SPIE vol 914, Medical Imag. ing II, 1988, pp 970-975

10. Ratib O, Huang HK: Integration of a desktop image analysis work station based on a Macintosh II computer in a clinical PACS. Scientific Exhibit \#915, RSNA 74th Sci Assy and Ann Meeting, Chicago, IL, 1988
11. ter Haar Romeny BM, Raymakers J, van Waes PFGM, et al: The Dutch PACS project: Philosophy, design of a digital reading room and first observations in the Utrecht University Hospital in the Netherlands. Proc SPIE vol 767, Medical Imaging, 1987, pp 787-792

12. Balter S, Janower ML: Radiographic viewing conditions. Proc SPIE, vol 43, Appl Opt Inst Med II, 1973, pp 225-227

13. Fischer Harry W: Radiology Departments: Planning, Operation, and Management: Ann Arbor, MI, Edwards Brothers, 1982

14. Scott Wendell G: Planning Guide for Radiologic Installations, Second Edition. Baltimore, Williams and Wilkins, 1966

15. Rogers DC, Johnston RE, Brenton BC, et al: Predicting PACS console requirements from radiologists' reading habits. Proc SPIE vol 536, Medicine XIII/PACS III, 1985, pp 88-96

16. Mun SK, Benson H, Welsh C, et al: Baseline study of radiology services for the purpose of PACS evaluation. Proc SPIE vol 914, Medical Imaging II, 1988, pp 978-987

17. Sanders MS, McCormick EJ: Human Factors in Engineering and Design, Sixth Edition. New York, McGrawHill, 1987

18. Mun SK et al: op cit, $p 985,1988$

19. Diffrient $N$, Tilley AR, Harman D: Humanscale $1 / 2 / 3,4 / 5 / 6$, and 7/8/9. Cambridge, MA, MIT Press, 1981

20. Sanders MS, McCormick EJ: op cit, p 432, 1987

21. Diffrient N, Tilley AR, Harman D: op cit, $4 / 5 / 6$ p 13, 1981

22. Sanders MS, McCormick EJ: op cit, pp 414-415, 1987

23. Tuddenham WJ: Rooms for Film Processing and Display, in Scott, WG (ed): op cit p 79, 1966 